\title{
EFFECTIVENESS OF GINGER TO REDUCE CHEMOTHERAPY- INDUCED NAUSEA AND VOMITING IN CANCER PATIENTS: A SYSTEMATIC REVIEW
}

\author{
Lya Fitriyani
}

Masters Program in Nursing, Univeristas Hasanuddin

\begin{abstract}
Background: Cancer is one of the leading causes of death in the world, and chemotherapy is the treatment of choice. Nausea and vomiting are more common side effects of chemotherapy. Ginger may be used as herbal therapy and complementary therapy to reduce this effect. The purpose of this review is to evaluate the effectiveness of ginger to reduce chemotherapy-induced nausea and vomiting.

Subjects and Methods: This study is a systematic review that compiles the results of publications from 2010-2020. This study used PubMed, ProQuest, Science Direct, and Google Scholar databases. The keywords in PICO (P: Cancer OR Chemotherapy; I: Ginger OR Ginger Extract; C: Usual care OR No Intervention; O: Nausea AND Vomiting).

Results: There were 6 RCT (Randomised Controlled Trials) articles, with the number of participants being 1,395 cancer patients. The results showed that ginger could be used as a non-pharmacological alternative therapy to reduce nausea and vomiting.

Conclusion: Ginger can be used as herbal and complementary therapy for cancer patients undergoing chemotherapy to reduce nausea and vomiting.
\end{abstract}

Keywords: ginger, nausea, vomiting, chemotherapy, cancer

\section{Correspondence:}

Lya Fitriyani. University of Hasanuddin. Perintis Kemerdekaan 11 Makassar, SouthCelebes. Email: kaloigaga19@gmail.com. Mobile: 085205590049. 